\title{
PLANNING SCHEDULING, TRACKING AND APPLICATION ADMINISTRATION USING PRIMAVERA WEB LOGIC P6
}

\author{
Mohammed ZakiHaider ${ }^{1}$, Rajendra.S ${ }^{2}$, Vijay.K ${ }^{3}$ \\ ${ }^{I}$ P.G Student, Department of Civil Engineering, N.C.E.T, Visvesvaraya Technological University, Bangalore, India \\ ${ }^{2}$ Professor and Head (P.G), Department of Civil Engineering, N.C.E.T, Visvesvaraya Technological University, \\ Bangalore, India \\ ${ }^{3}$ Associate Professor, Department of Civil Engineering, N.C.E.T, Visvesvaraya Technological University, Bangalore, \\ India
}

\begin{abstract}
Proper planning, scheduling, tracking and application administration are the major parameter in construction industry. The systematic flow of work is adopted by using techniques called Critical Path Method (CPM) and Programme Evaluation and Review technique (PERT). The state for management of the project .and the goal intended to attain project planning is to bring forth a time table of work with each activities. The main goal intended from the project is to complete with proper plan and schedule within the gross budget allotted for actual project. The complete process of using resources and to achieve quality in construction can be done by proper project management. The Oracle primavera p6 software includes all possible details to scale with multi-project planning control even for a wide range of projects, thus proper resource allocation and project portfolio management can be achieved by sitting on single system. Planning, scheduling, tracking and administration application in primavera is an advance technology in construction industry which requires the study of material, manpower, improved design and hence improves the construction management technique.
\end{abstract}

Keywords: Planning, Scheduling, Tracking, Organization, Portfolio, Construction management, Activities, Resources, Material

\section{INTRODUCTION}

Working project in primavera is like a working in Group of activities with a systematic work breakdown structure. Which may need a latest knowledge and specialize skill in each particular activities that's lead to the most systematic flow of work. This systematic flow of work is adopted by using techniques called Critical Path Method (CPM) and Programme Evaluation and Review technique (PERT) are two state for management of the project the goal intended to be attained of a project planning is to bring forth a time table of work with each activities distribute according to a plan a start date and finish date.

Primavera is an advance computer integrated enterprise project management tool. As we know India is booming in construction industry so we should be familiar with tools like primavera which is highly advance management tool with recorded data base ORACLE this tool is web assessable for modification in an any situation in management activities this tool work simultaneously for multi project at a time can be monitor and control all the project.so proper management is required with documentation and this can be possible if we know primavera tool completely and properly.

\subsection{Scope of Project in Construction Industry}

Planning scheduling is one of the important part in construction industry because it's give the exact idea of time and cost in the construction project.

- Tracking and application administration with web asses give an extra feature to this primavera Tool

- Reducing the huge amount of paperwork from the construction site lead to paperless site

- To identifying the main reason of delay of the project and reducing those delay of work as initially considering the risk management

- In future time and money is going to be very important consideration so those two things can be control in day/weekly/monthly/yearly wise in primavera

\section{LITERATURE REVIEW}

B.S.K Reddy, SkNagaraju and Md Salman (2015): In this they describe the important of resources allocation by taking two ongoing project of Dubai (UAE). They carried out the informal interview with the site supervisor and project manager. They collected the required data for the resources levelling for both the project. Based on optimization of resources for the project. A company can improve the profitability and productivity of the organization. [1] 
Shaikh Mohammed Masood, Devand and Harsh H.N (2014): A case study of duplex apartment has been taken for analysis of resources planning of cost estimation and tracking of the project. They have adopted earn value management technique. That is use for work forecast in progress. To know what will happen in future with respect to cost estimation of the project. The base line is set to control the cost. The main purpose to adopt earn value analysis is to analysis the whole cost change in resulting in time, cost overrun of the project. So that corrective measure to be taken. Schedule used to predict the advance future performance of the project completion. [2]

PeltheSaranges and PramilaAdavi (2012): They describe about the various application in primavera with a concept of computer integrated enterprise project management. The application of organization is a breaking down structure of a project for a responsible manner .The application resources optimization for proper productivity. The application of risk management for priority level and the project cost and project current date can't be change. [3]

Divya R and S.Ramya (2015): The main objective of the author is to identify the major causes of delay, effect of delay and method of minimizing delay in construction project. Data has analysis to establish the relative importance of various factor that provides a particular quality or character to cause the effect in construction delay. [4]

Unmesh.YPolekar and Rohit.RSalgude (2015): The author describe about construction planning and challenging activities in management work during the execution. The scheduling is done for time management of each event or activities in the project. The tracking is done for actual project performing value. But it's a small residential building having very less activities. The importance of the planning, scheduling and tracking of the residential project using primavera is to know the comparison between planned and actual executed schedule. [5]

\section{METHODOLOGY AND ANALYSIS-1}

I worked as intern in NCC ltd. as per the VTU prescribed syllabus in 3rd semester. It was a great opportunity to work in construction industry people. The worked closely and followed the construction of NCET Hostel Block at NCET campus. The period of my internship was 4 months. I closely monitored all the work which was been going out there and the experience with the people working there give me a brief idea about working on my M.Tech project. The data which I collected during my internship period help me to do the project. The idea of project title is "planning, scheduling, tracking and administration application using ORACLE primavera web logic P6".The construction work is a complicated work with a vast documentation work. So the purpose of the software came into existence to simplify the work. ORACLE Primavera is purely project management software. The Primavera P6 is used for planning, scheduling, tracking and application administration.

The following methodology and analysis-1 for step involved in ORACLE Primavera P6 to do planning and scheduling of the project

$>$ Accumulate the drawing from company

$>$ Abstract of the quantities

$>$ Generate OBS of the project

$>$ Generate EPS of the project

$>$ Generate new project

$>$ Generate a calendar of the project

$>$ Create WBS of the project

$>$ Generate and define each activities of the project

$>$ Assign logic links/relationship of the project

$>$ Scheduling of the project

$>$ Role \& Resource of the project

$>$ Assign \& Resource of the project

$>$ Resource analysis \& levelling of the project

\section{METHODOLOGY AND ANALYSIS-2}

This methodology and analysis-2 for the step involved in ORACLE Primavera P6 to tracking and application administration of the project

$>$ Generate baseline of the project.

$>$ Updating progress of the project.

$>$ Tracking progress of the project.

$>$ Budgeting of the project.

$>$ Funding of the project.

$>$ Portfolio of the project.

$>$ Dashboards of the project

$>$ Team member of the project.

\section{RESULTSAND DISCUSSION ON THE PROJECT}

$\checkmark \quad$ The total number of the activities nearly 800 which give the complete clarity of planning of a project these 800 activities is divided on various work breakdown structure.

$\checkmark \quad$ Totally there are 3 type of resources in primavera. All together nearly 100 resources $\mathrm{i}$ used in my project to allocate properly. The more we have resources the more we can do proper plan. All resources are different due to different skilled Labours required in construction site.

$\checkmark \quad$ There are 502 days required for construction of NCET hostel block to complete including structural and finishing work this duration is possible when the project goes on time with planned project duration then it's possible to complete in 502 days .where actual project is still under construction only. 


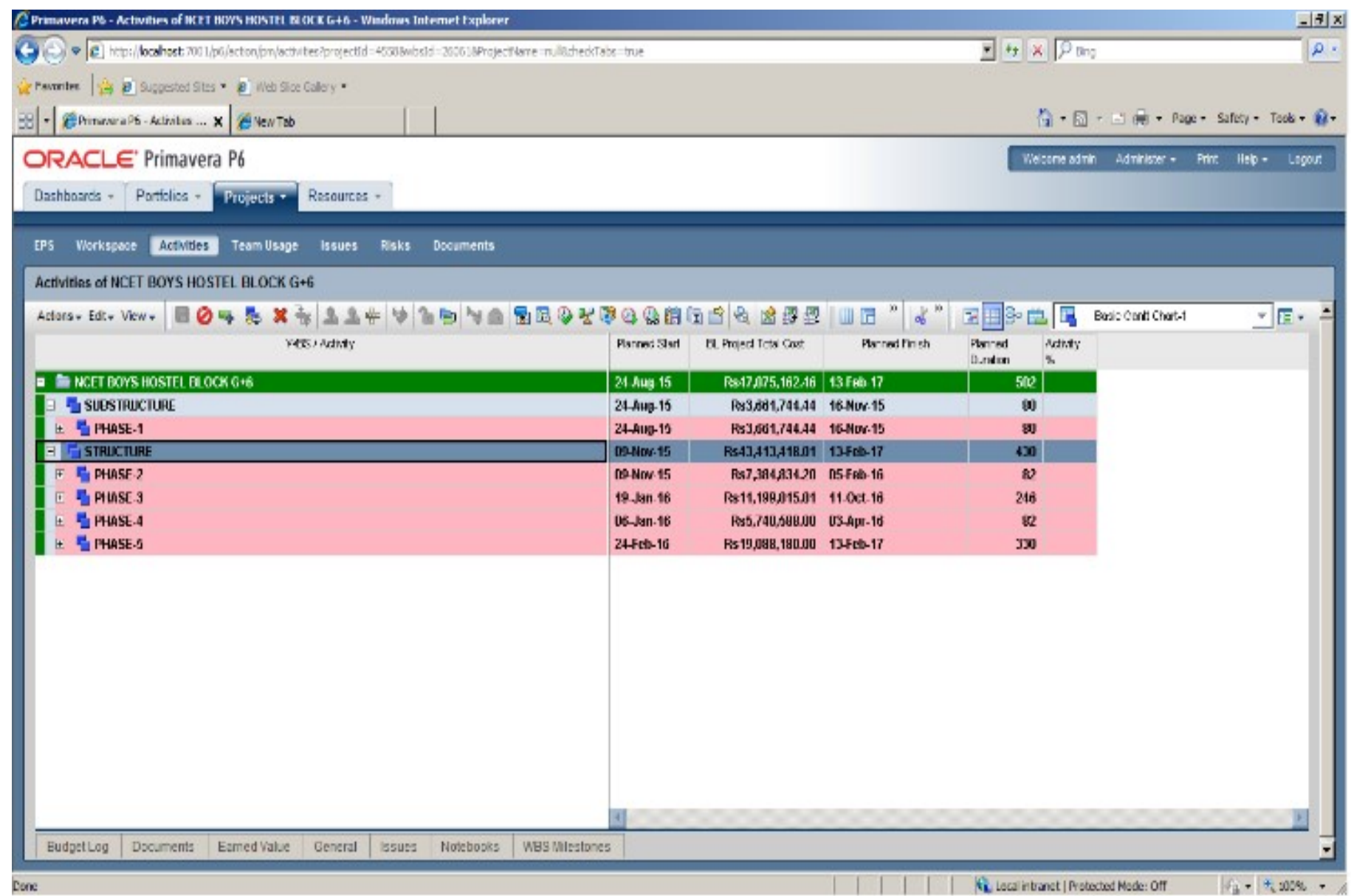

Fig -1: Days in each phases

Phase 1: Total planned duration took by phase one is 80 days in these 77 days we can able to complete the initialization work, excavation work and column up to ground floor with plinth beam construction. The most critical work in phase1 is footing work. Total planned duration required is 67 days

Phase 2: Total planned duration took by phase two is 82 days in these 82 days we can able to finish the structural work from ground floor to third floor structural work like column work beam slab of all floor of phase2. The most critical work in phase 1 is obtain and its beam slab $\mathrm{d}$ shuttering. The most critical work in phase 1 is slab beam of $60 \%$ workside.

Phase 3: Total planned duration took by phase three is 246 days .we can able to finish the finishing work from ground floor to third floor finishing work like masonry, flooring ,waterproofing, doors and windows and painting etc. The most critical work in phase 3 is obtain and it's plastering work
$>$ Phase 4: Total planned duration took by phase four is 82 days in these 82 days we can able to finish the structural work from fourth to terrace floor. Structural work like column work beam slab of all floor of phase 4 . The most critical work in phase 4 is obtain and its beam slab d shuttering. The most critical work in phase 1 is slab beam of $60 \%$ workside.

> Phase 5: Total planned duration took by phase five is 330 days .we can able to finish the finishing work from fourth floor to terrace . Finishing work like masonry, flooring, waterproofing, doors and windows and painting etc. The most critical work in phase 5 is obtain and it's plastering work 


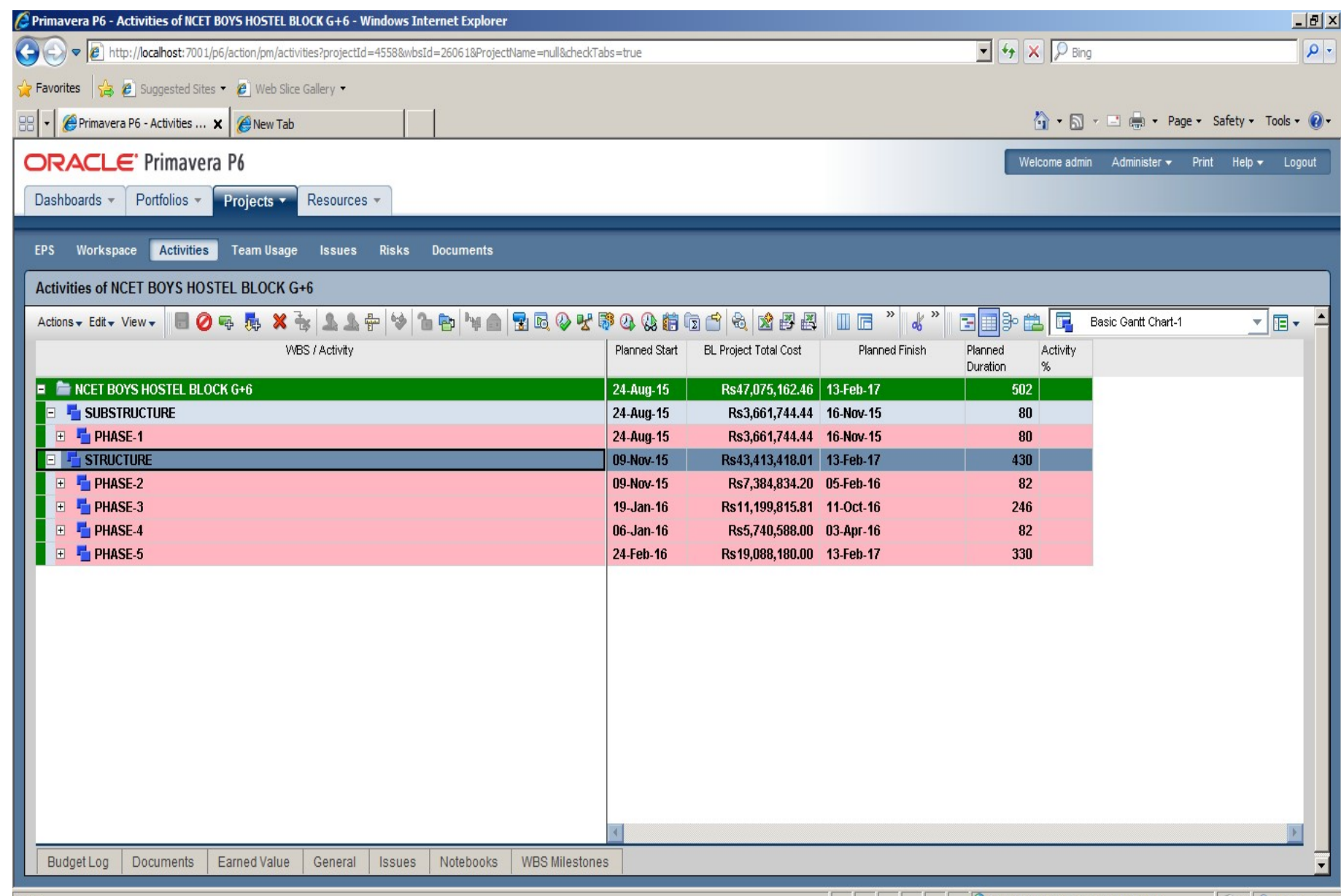

Fig -2: Cost of each phases

Phase 1: The first phase cost is Rs3,661,744.00/- and extra some lumsum amount has to add for other works. So this amount is required to finish the work for phase 1 this amount is lesser than the actual used in the site so planning in primavera reduce the cost of construction in phase 1 .

$>$ Phase 2: The second phase cost is Rs7,384,835.00/- and extra some lumsum amount has to add for other works .so this amount is required to finish the work for phase 2 of all structural work of phase 2 this amount is lesser than the actual used in the site so planning in primavera reduce the cost of construction.in phase 2 .

$>$ Phase 3: The third phase cost is Rs11,199,816.00/- and extra some lumsum amount has to add for other works .so this amount is required to finish the work for phase 3 of all finishing work of phase 3.This amount is lesser than the actual used in the site so planning in primavera reduce the cost of construction.in phase 3 .
Phase 4: The fourth phase cost is Rs5,740,588.00/-and extra some lumsum amount has to add for other works .so this amount is required to finish the work for phase 4 of all structural work of phase 4 this amount is lesser than the actual used in the site so planning in primavera reduce the cost of construction.in phase 4 .

$>$ Phase 5: The fifth phase cost is Rs19,088,180.00/-and extra some lumsum amount has to add for other works .so this amount is required to finish the work for phase 5 of all finishing work of phase 5 . This amount is lesser than the actual used in the site so planning in primavera reduce the cost of construction.in phase 5 .

\subsection{Resources Levelling}

The levelling of the resources is one of the toughest job in primavera it's a based on the maximum availability of resources. The following photos are over allocated before allocating the maximum unit/time. 


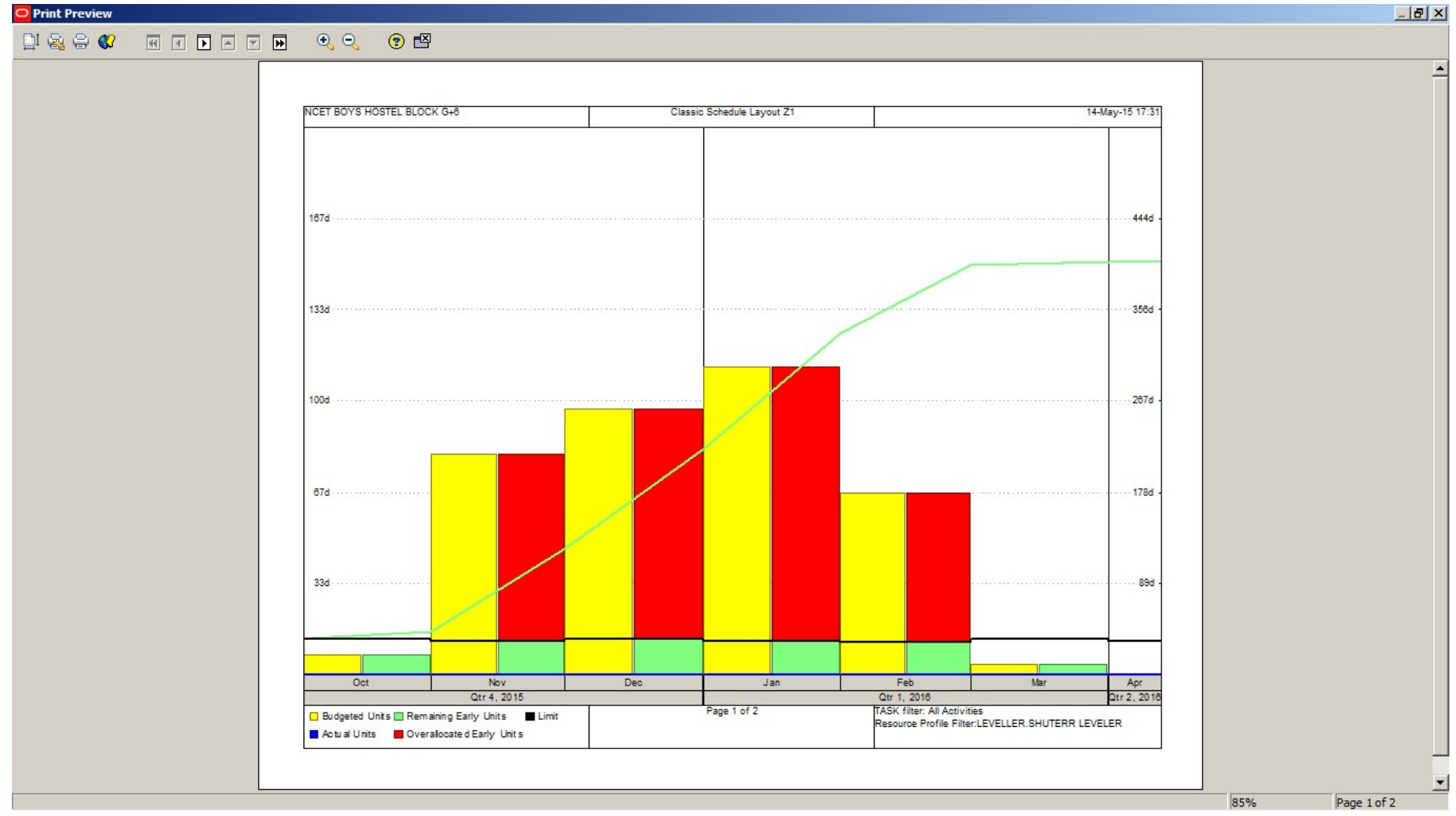

Chart -1: over allocated of shutter leveler

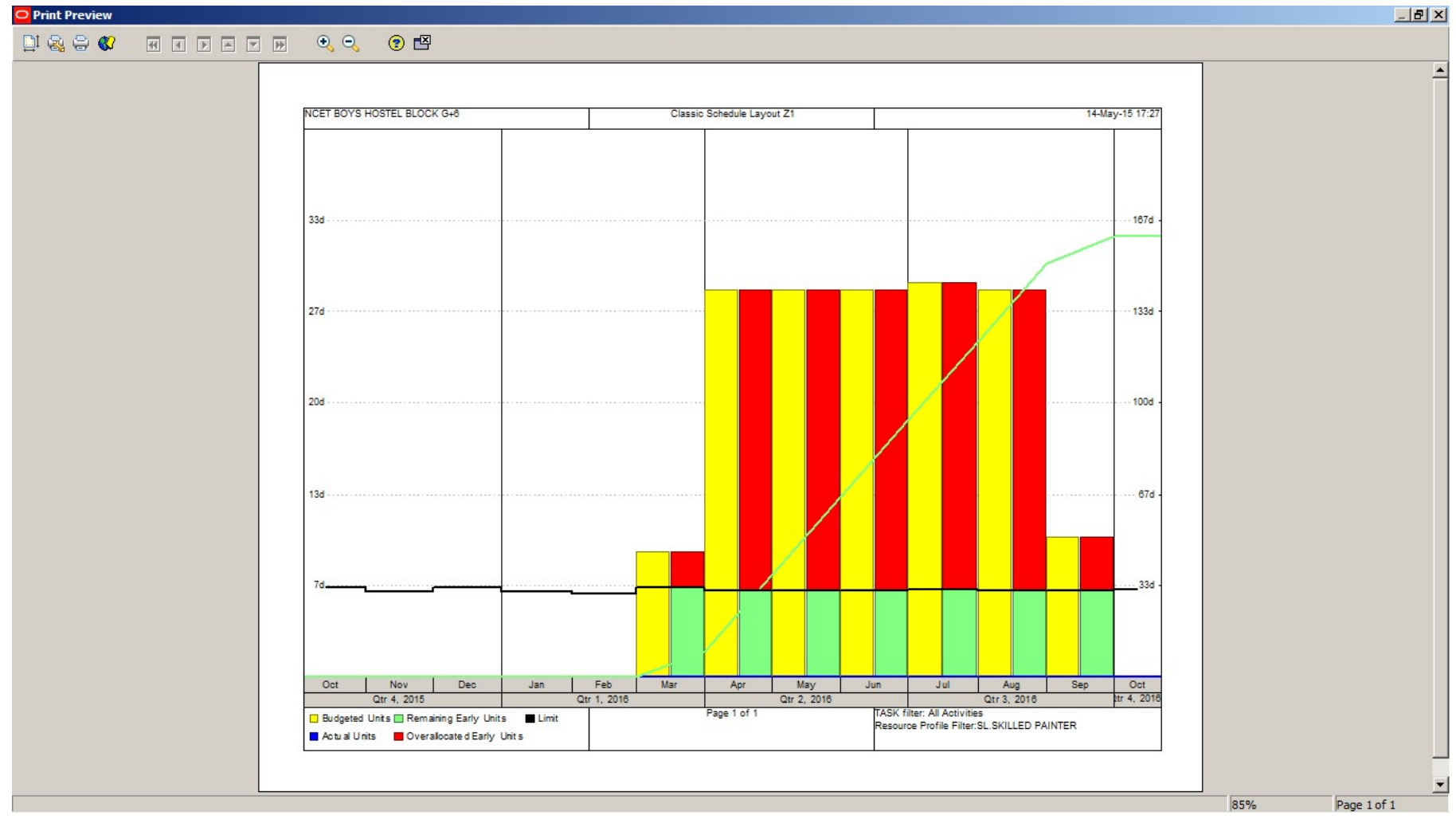

Chart -2: over allocated of site engineer

The following are the result of levelled these analysis will give a better results to utilize optimum resources allocation. These is done for effective resources management .once resources analysis is done almost project planning and scheduling is done. 


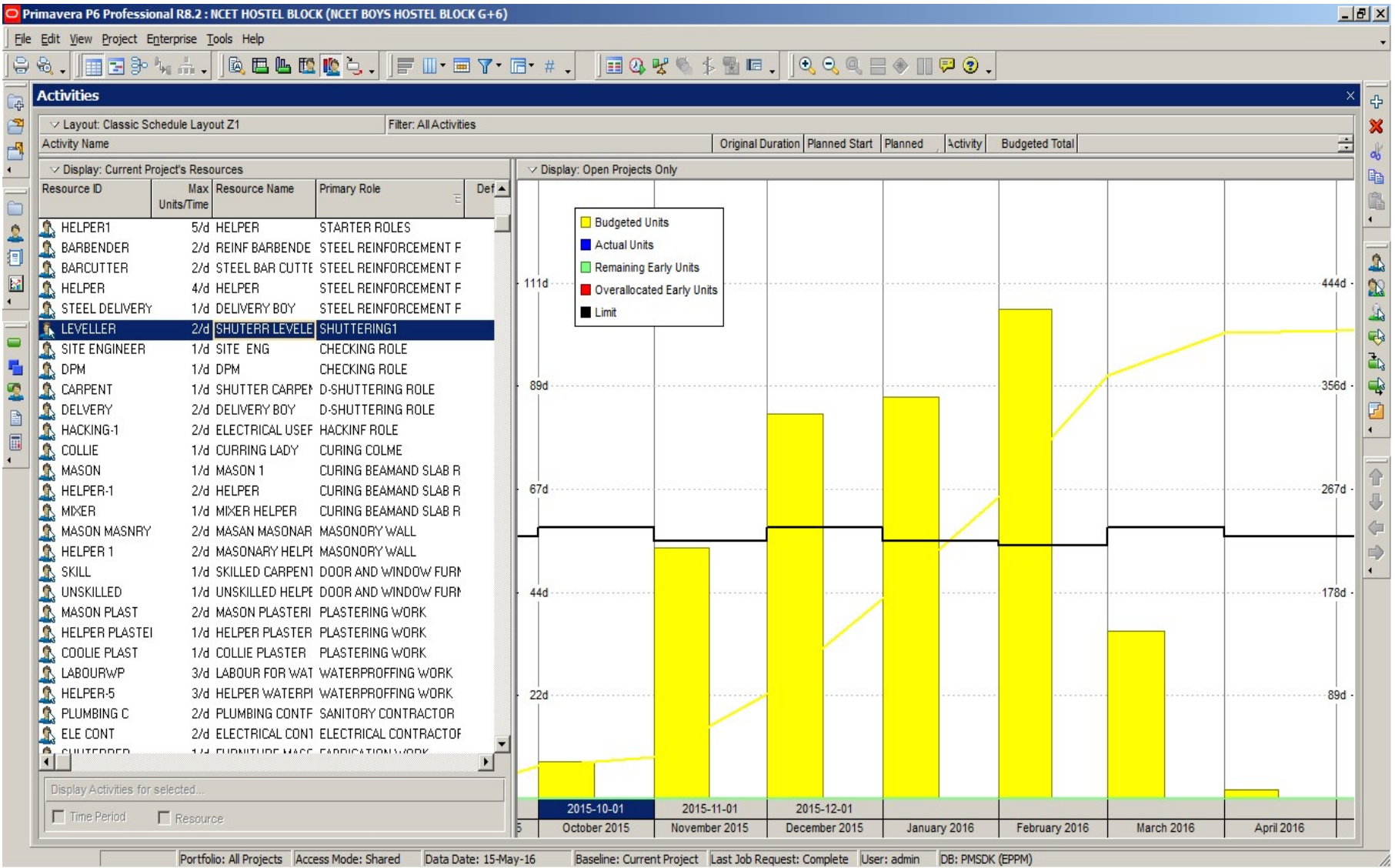

Chart -3: Levelled of shutter leveler

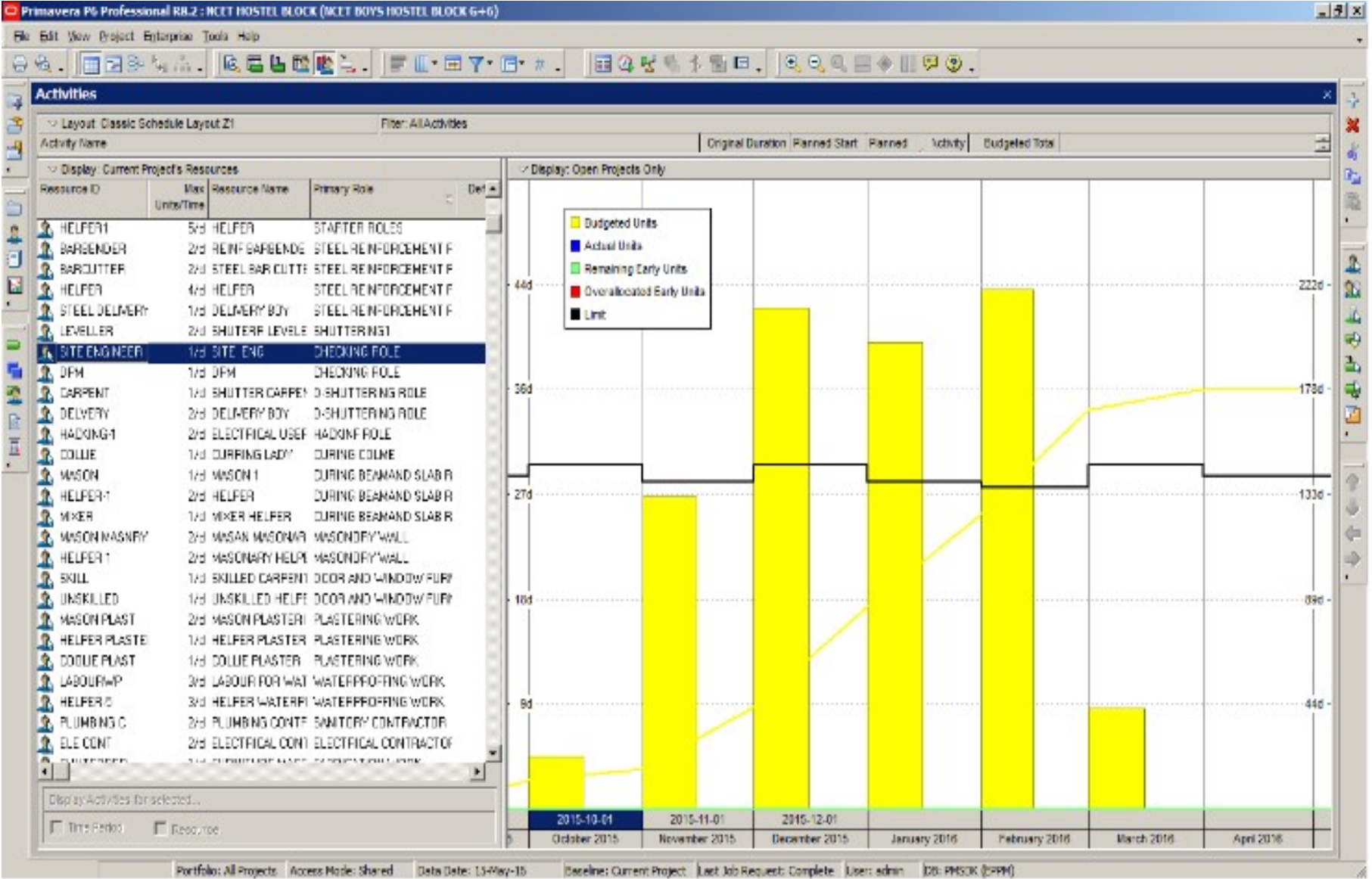

Chart -4: Levelled of site engineer 


\section{CONCLUSION}

The oracle primavera P6 web logic is highly advance compare to primavera standard Oracle primavera alone P6 in terms of planning, scheduling, and tracking for any company project.

$\checkmark$ Creating "WBS child" is an easy task in primavera Web logic.

$\checkmark$ Proper planning software with details will help to analyses the project planning more wisely.

$\checkmark \quad$ Finding drawbacks or setbacks in planning is possible only when activities are very detail and clear.

$\checkmark$ Proper management like assigning team for each resources or role to resources during creating the resources will provide less burden in assigning the resources to the activities.

$\checkmark$ Due to web access a single project can be accessed from multiple users from any part of the world. The security can be maintained by providing individual log in id and password.

$\checkmark$ Planning and scheduling of project will provide us a detail information about:

$\checkmark$ Cost control.

$\checkmark$ Time management.

$\checkmark$ Working hour's management.

$\checkmark$ Update and Monitoring.

$\checkmark \quad$ Delay of activities with reasons.

$\checkmark$ Paper less project management at site.

$\checkmark$ Comparing multiple projects simultaneously is very easy in primavera web logic P6 portfolios tab.

$\checkmark$ Proper optimization of resources is possible during the levelling of the resources based on required condition and constraints.

\section{FUTURE SCOPE OF THE PROJECT}

$\checkmark \quad$ The project was executed by a single user involvement, multiple users can also perform on a single project if the project size is massive.

$\checkmark \quad$ The project can also be executed for multiple projects considering the same parameters or more.

$\checkmark \quad$ The project could further be detailed with funding and cash flow representation and management.

$\checkmark \quad$ The project can also be worked for delay consideration while scheduling.

$\checkmark$ Monitoring can be done properly in dashboard tab as I have considered only Project Manager's budget, whereas we can also do for resources, earn value and activities.

$\checkmark$ The loss or profit for a project in terms of rate of interest can be obtained along with the income tax return for which a separate project can be prepared and studied.

\section{ACKNOWLEDGEMENT}

The study could not have been completed without the aid and assistance of our dear Principal. We would like to thank him for all his effort in guiding us. We would like to thank all the authors of various journals and books for enlightening us with their knowledge. We are grateful to our family, friends and the Department of Civil Engineering.

\section{REFERENCES}

[1]. B. S. K. Reddy, SK. Nagaraju, Md. Salman, (2015), “a Study on Optimisation of Resources for Multiple Projects by Using Primavera" Journal of Engineering Science and Technology Vol. 10, No. 2

[2]. Shaik Mohammad Masood, Devanand.R, Harsha H.N (2014)," An Analysis on Resource Planning, Cost Estimation and Tracking of Project by Earned Value Management" ISO 9001:2008 Certified International Journal of Engineering and Innovative Technology (IJEIT) Volume 4, Issue 4

[3]. PetheSarang S \&PramilaAdavi (2012)," Application Of Primavera In Construction Industry" International Journal of Advanced Technology in Civil Engineering, ISSN: $2231-$ 5721, Volume-1, Issue-3, 4

[4]. Divya.R1, S.Ramya (2015), "Causes, Effects and Minimization of Delays in Construction Projects" National Conference on Research Advances in Communication, Computation, Electrical Science and Structures

[5]. Unmesh. Y. Polekar, Rohit. R. Salgude,(2015), "Planning, Scheduling and Tracking of a residential Project using Primavera Software", International Journal of Advance Research in Computer Science and Management Studies, Volume 3, Issue 5,

[6]. MladenVukomanović, MladenRadujković, ZlataDolačekAlduk (2012)" The Use of Project Management Software In Construction Industry of SouthEast Europe"

Primjenaračunalnihaplikacijazaupravljanjeprojektima u građevinskojindustrijiJugoistočne Europe

[7]. Abusalah Mohamed AlakhdarAbdlaziz, R.K. Pandey, Prabhat Kumar Sinha,AshokTripathi, Anshuman, (2013) "Time and Schedule Management by Using Primavera" International Journal of Civil Engineering and Technology (IJCIET), ISSN 0976 - 6308 (Print), ISSN 0976 6316(Online) Volume 4, Issue 5. [4]. Reference 4

\section{BIOGRAPHIES}

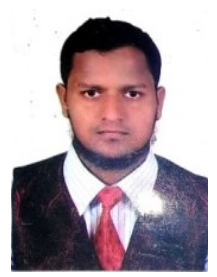

Mr., MOHAMMED ZAKI HAIDER Obtained his bachelor of engineering (Civil Engineer) from Anjuman Institute of Technology and Management and Master in Technology (Construction Technology) from Nagarjuna college of engineering and Technology .I worked as intern in NCC Lmt Company

Mr. Dr. S RAJENDRA presently he is working as professor and head of P.G civil department in Nagarjuna college of engineering and technology Bangalore india

Mr. VIJAY $\mathbf{K}$ presently he is working as Associate professor of civil department in Nagarjuna college of engineering and technology Bangalore india 